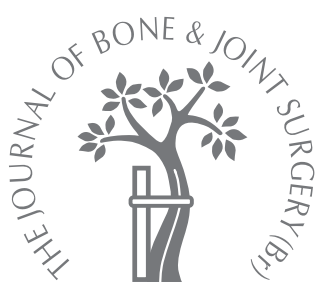

S. Muirhead-

Allwood,

N. A. Sandiford,

J. A. Skinner,

J. Hua,

W. Muirhead,

C. Kabir,

P. S. Walker

From The London

Hip Unit, London,

United Kingdom

S. Muirhead-Allwood, FRCS

Consultant Orthopaedic

Surgeon

N. A. Sandiford, MRCS,

MFSEM, Specialist Registrar

W. Muirhead, BA(Hons)

BMBS

C. Kabir, MRCS, Clinical

Research Fellow

The London Hip Unit, 4th Floor,

30 Devonshire Street, London

W1G 6PU, UK.

J. A. Skinner, FRCS(Orth),

Consultant Orthopaedic

Surgeon

J. Hua, PhD, Director

Department of Biomedica

Engineering

Royal National Orthopaedic

Hospital, Brockley Hill,

Stanmore HA7 4LP, UK.

In S. Walker, MD, Professor, Director

MIS Laboratory, Department of Orthopaedic Surgery

NYU Medical Center, Hospital

for Joint Disease, 301 East 17th

Street, Manhattan, New York,

10003, USA.

Correspondence should be sent to Miss S. Muirhead-Allwood; e-mail: Iondonhip@aol.com

(C)2010 British Editorial Society of Bone and Joint Surgery doi:10.1302/0301-620X.92B10. $23124 \$ 2.00$

$J$ Bone Joint Surg [Br] 2010;92-B:1370-5.

Received 21 July 2009;

Accepted after revision 4 May

2010

\section{Uncemented computer-assisted design- computer-assisted manufacture femoral components in revision total hip replacement}

\author{
A MINIMUM FOLLOW-UP OF TEN YEARS
}

\begin{abstract}
We prospectively evaluated the long-term outcome of 158 consecutive patients who underwent revision total hip replacement using uncemented computer-assisted designcomputer-assisted manufacture femoral components. There were 97 men and 61 women. Their mean age was 63.1 years (34.6 to 85.9). The mean follow-up was 10.8 years (10 to 12 ).

The mean Oxford, Harris and Western Ontario and McMaster hip scores improved from 41.1, 44.2 and 52.4 pre-operatively to $18.2,89.3$ and 12.3 , respectively ( $<0.0001$, for each). Six patients required further surgery. The overall survival of the femoral component was $97 \%$ (95\% confidence interval 94.5 to 99.7$)$. These results are comparable to those of previously published reports for revision total hip replacement using either cemented or uncemented components.
\end{abstract}

The United Kingdom National Joint Registry has reported an increase in the number of revision total hip replacements (THRs) of over $250 \%$ between 2003 and 2006 (from 2325 to 6145 cases). ${ }^{1}$ The first generation of cemented revision THR produced some unsatisfactory results. ${ }^{2,3}$ Technical advances in implant design and surgical techniques have improved survival but significant rates of loosening and bone loss have persisted. ${ }^{4-10}$ Complications have also been associated with the use of uncemented femoral components, including subsidence ${ }^{9,11}$ and proximal femoral fractures. ${ }^{12}$

The variability of the endosteal geometry after removal of the femoral component can make proximal fit and fill difficult to achieve with an 'off the shelf' prosthesis. Whatever the anatomy of the proximal femur, it is important to achieve immediate stability, preserve bone stock and protect the femur from cortical defects which can lead to subsequent fracture. ${ }^{13}$ In revision THR this requires a large inventory of modular femoral components. The use of a computer-assisted designcomputer-assisted manufacture (CAD-CAM) prosthesis obviates this need. Encouraging short-term results have been reported with the use of custom femoral components in revision cases with extensive loss of femoral bone stock. ${ }^{14}$ However, little has been published on the use of custom-made components in revision THR. We report the results of a large cohort of patients who underwent revision THR using CAD-CAM femoral components.

\section{Patients and Methods}

A total of 158 consecutive patients, with no exclusions were included in this prospective study. All patients who underwent revision THR between November 1991 and November 1998 were treated using CAD-CAM femoral components. There were 97 men and 61 women. Their mean age was 63.1 years (34.6 to 85.9). The indications for revision are shown in Table I. Age distribution is shown in Table II.

All operations were performed by the senior author (SMA) via a posterior approach without an extended trochanteric osteotomy. A HarrisGalante I (Zimmer, Warsaw, Indiana) was used in 68 patients $(43 \%)$ and a Trilogy (Zimmer) component in the remainder.

Uncemented acetabular components were used in all but one case when revision of the acetabular component was indicated. In the case where a cemented component was used, the acetabular defect required impaction allografting, followed by insertion of a reconstruction cage into which a highly cross-linked polyethylene liner was cemented.

The custom-made revision femoral components were manufactured by the Biomedical Engineering Unit (Stanmore Implants Worldwide, Stanmore, United Kingdom). The scanning protocol included a true anteroposterior (AP) radiograph of the pelvis and a lateral view of the affected hip. In order to standardise for magnification, a radio-opaque ruler was placed adjacent to the pelvis and the radiographs were 
Table I. Patient characteristics and indications for revision

\begin{tabular}{|c|c|}
\hline & Number of patients \\
\hline Total & 158 \\
\hline Men & 97 \\
\hline Women & 61 \\
\hline Mean age in years (range) & 63.1 (34.6 to 85.9) \\
\hline Male & 63.7 (36.0 to 83.4 ) \\
\hline Female & 61.6 (34.6 to 80$)$ \\
\hline \multicolumn{2}{|l|}{ Indications for revision } \\
\hline Aseptic loosening & 136 \\
\hline Infection & 12 \\
\hline Periprosthetic fracture & 6 \\
\hline Recurrent dislocation & 3 \\
\hline Liner wear & 1 \\
\hline
\end{tabular}

Table II. Age distribution of patients

\begin{tabular}{lc}
\hline Age (yrs) & Number of hips \\
\hline 30 to 39 & 7 \\
40 to 49 & 19 \\
50 to 59 & 29 \\
60 to 69 & 46 \\
70 to 79 & 49 \\
80 to 89 & 8 \\
\hline
\end{tabular}

sent to the manufacturer to create a computer-assisted design which, once approved by the surgeon, formed the template for the final product. This was delivered to the hospital with a tapered reamer and a custom-made rasp. Each femoral component was manufactured from titanium alloy, $\mathrm{Ti}_{6} \mathrm{~A} 1_{4} \mathrm{Va}$, with a proximal segment which produced the closest possible line-to-line fit with the endosteal border of the femur. This segment was grit-blasted and coated with an $80 \mu \mathrm{m}$ thick layer of hydroxyapatite (HA) with high crystallinity. All the components had a collar and a lateral flare in order to minimise axial displacement, theoretically improving stability. The design of the distal aspect of the component was based on the degree of femoral bone loss as classified by Pak et al. ${ }^{15}$ For type 1 defects components of $120 \mathrm{~mm}$ to $140 \mathrm{~mm}$ in length were used (Fig. 1). For type 2 defects components of $140 \mathrm{~mm}$ to $200 \mathrm{~mm}$ with a HA coating on the proximal third and a smooth distal aspect to facilitate their entry and centralisation in the femoral canal were used (Fig. 2). For type 3 defects, components of $140 \mathrm{~mm}$ to $200 \mathrm{~mm}$ were used (Fig. 3). These were fully coated to achieve maximal osseo-integration and with longitudinal cutting flutes to achieve maximal torsional stability. ${ }^{16-18}$ Where necessary, the components had an anterior bow to fit the anatomy of the femur.

All patients were reviewed clinically and radiologically at six weeks, three months, and annually thereafter. Function was assessed using the Oxford, ${ }^{19}$ Harris $^{20}$ and Western Ontario and McMaster (WOMAC) ${ }^{21}$ hip scores, and any complications were recorded. Assessment was undertaken

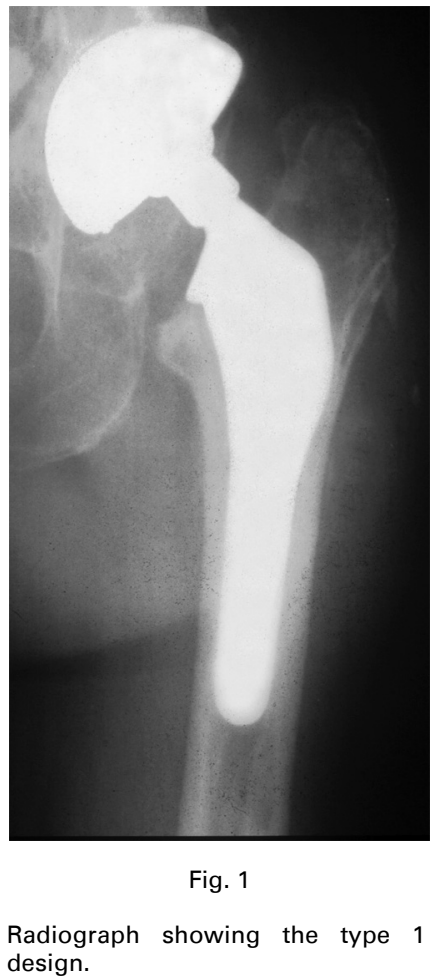

by two independent observers (NAS, CK), who also reviewed the radiographs for radiolucent lines, and for signs of stable fixation of the femoral component, including advancement of bone trabeculae to the stem-cement interface, spot welding at the bone-stem implant interface, and any evidence of migration. ${ }^{22}$ Radiolucent lines were defined as linear lucencies at the bone-prosthesis interface $>2 \mathrm{~mm}$ wide and occupying $>30 \%$ of any Gruen zone. Lytic lesions were defined as balloon shaped lesions without sclerosis. ${ }^{23}$ Proximal femoral defects were classified by the Paprosky system. ${ }^{15}$ Loosening of the acetabular component was classified according to the system described by DeLee and Charnley. ${ }^{24}$ Statistical analysis. Analysis was performed using the unpaired Student's $t$-test (GraphPad, La Jolla, California). The level of significance was set at $p=0.05$. Kaplan-Meier survival analysis was performed and failure was defined as revision of the femoral component for any reason.

\section{Results}

The mean follow-up was 10.8 years (10 to 12$)$. No patient was lost to follow-up. All patients had relief of pain. The mean flexion of the hip was $95^{\circ}\left(90^{\circ}\right.$ to $\left.110^{\circ}\right)$.

The mean Oxford, Harris and WOMAC scores improved from 41.1 (15 to 60), 44.2 (7 to 91 ) and 52.4 (10 to 96 ) pre-operatively to 18.2 (12 to 49 ), 89.3 (35 to 100 ) and 12.3 ( 0 to 62 ), respectively ( $p<0.0001$ for each; Fig. 4). Three patients had intermittent anterior thigh pain with activity: each had Paprosky type 3 femoral bone defects and were treated with long-stemmed components. 


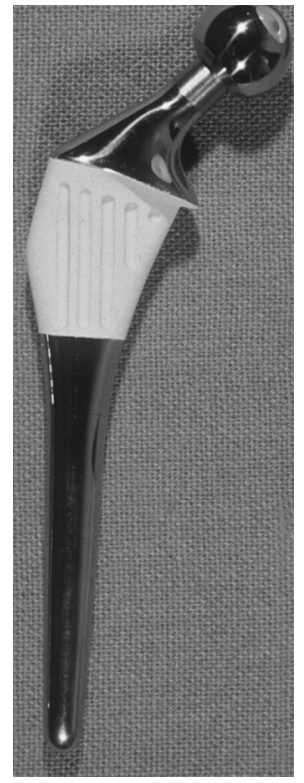

Fig. 2a
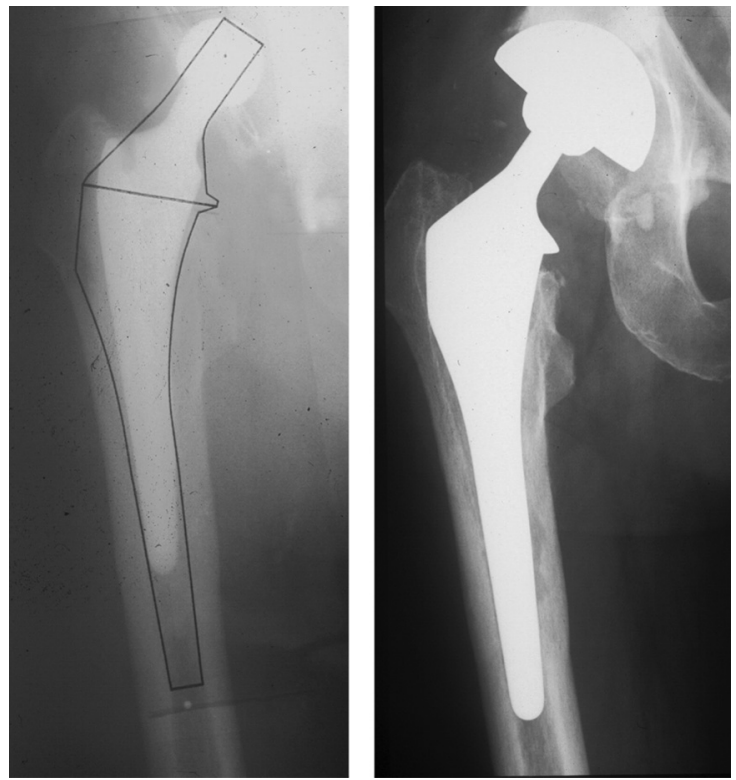

Fig. 2b

Images showing a) type 2 design and b) planning radiographs. The stem of this component is highly polished along its distal two-thirds, facilitating accurate positioning in the femoral canal.

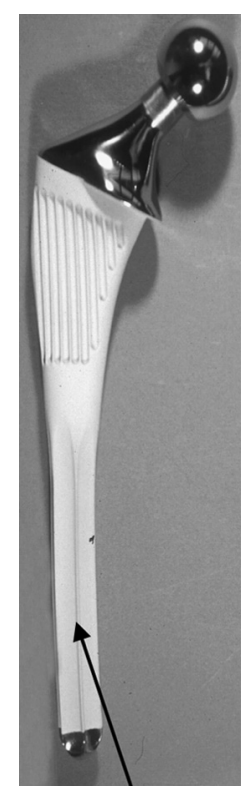

Fig. 3a
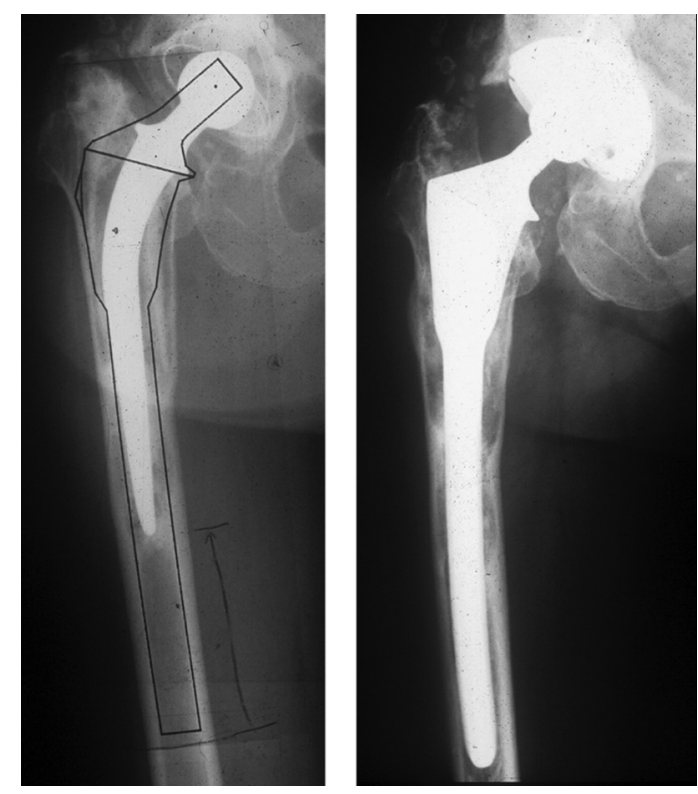

Fig. 3b

Images showing a) type 3 design and b) showing the design planning radiographs. The stem is coated with hydroxyapatite to facilitate osseo-integration and fluted to obtain torsional stability.

All femoral components were well fixed radiologically at the time of the final follow-up. Two $(1.3 \%)$ had subsided by $2 \mathrm{~mm}$ and $3 \mathrm{~mm}$, respectively, on AP radiographs taken three years post-operatively, but stabilised thereafter. Radiolucent lines $>2 \mathrm{~mm}$ wide were noted in five patients $(1.9 \%)$. These were in Gruen zones 1, 2 and 7. These patients were asymptomatic (Table III).
Evidence of stress shielding was noted in two hips (1.3\%), and these patients were also asymptomatic. Heterotopic ossification was noted in 22 hips (13.9\%). These were all stage 1 to 2 according to the classification of Brooker et al. ${ }^{25}$

Complications occurred in six hips $(3.8 \%)$. There were two posterior dislocations, one four days and one five years post-operatively. The first required revision 


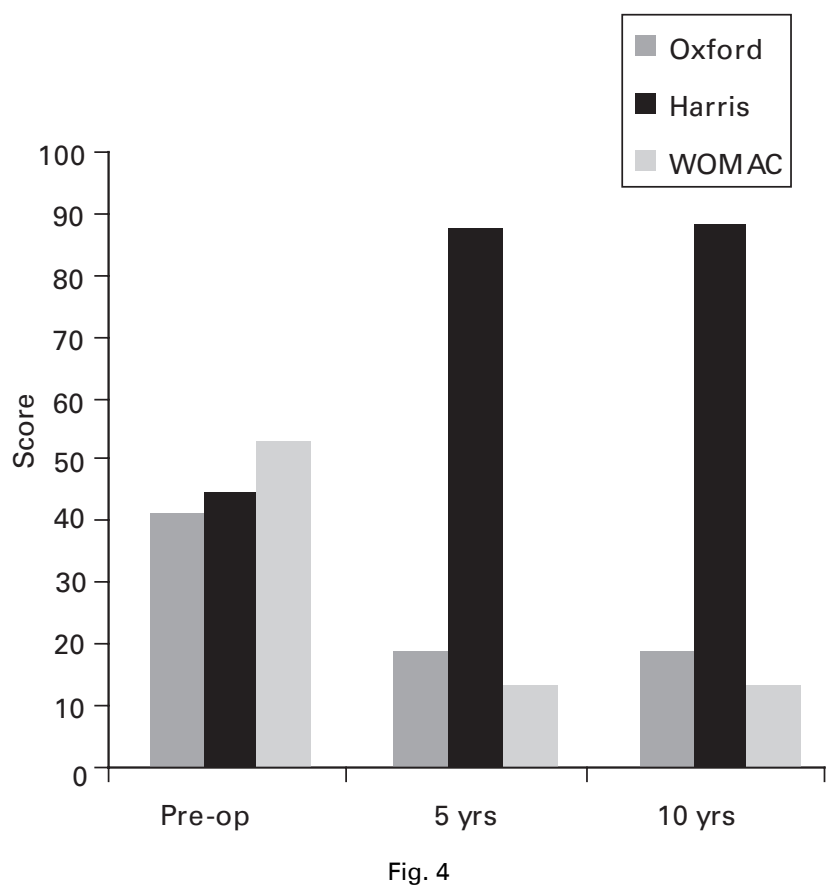

Bar chart showing the trend in hip scores over ten years.

Table III. Hips with signifi-
cant radiolucent lines based
on the zones of Gruen
\begin{tabular}{ll} 
Zone & Number of hips \\
\hline I & 1 \\
II & 2 \\
III & 0 \\
IV & 0 \\
V & 0 \\
VI & 0 \\
VII & 2 \\
\hline
\end{tabular}

for acetabular malalignment. Two patients had a deepvein thrombosis and one of these a pulmonary embolus. One patient suffered an undisplaced oblique periprosthetic fracture one month post-operatively. This was treated using stainless steel cables and eventually united after two years.

There were six revisions, one for instability four days post-operatively, one for peri-prosthetic fracture, three for aseptic loosening of the femoral component (at 5, 10 and 11 years post-operatively) and one for liner wear 12 years post-operatively. No hip developed infection. The ten-year survival, with failure defined as revision for any reason, was $97 \%$ (95\% confidence interval, 94 to 99.7, Fig. 5).

\section{Discussion}

Most patients requiring revision THR have proximal femoral bone loss, ${ }^{26}$ which can be compounded by further iatrogenic bone loss that can occur during extraction of the

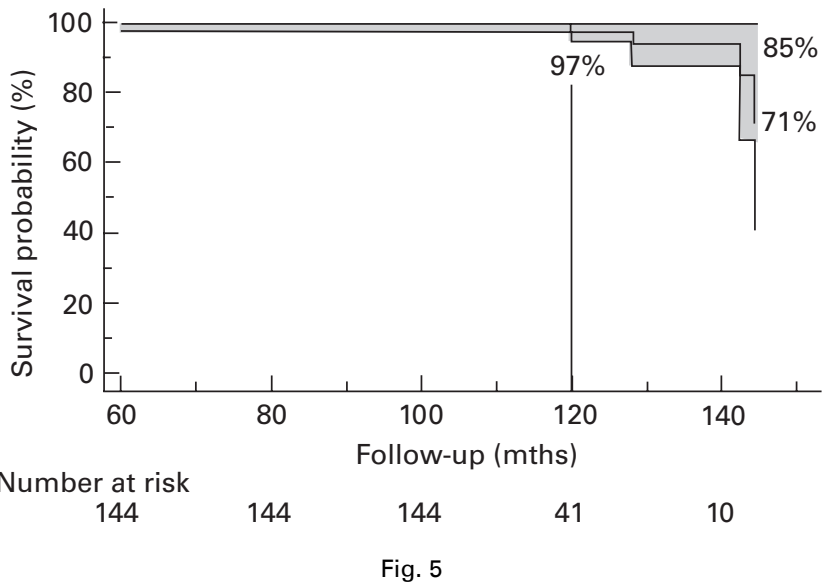

Kaplan-Meier survival plot with $95 \%$ confidence intervals. Survival at ten years was $97 \%$

femoral component. There is also considerable natural variation in the shape of the proximal femur. ${ }^{27}$ The goals of revision surgery include resolution of pain, as close as possible restoration of biomechanics and preservation of bone stock, all with minimal risk to the patient.

The philosophy of the CAD-CAM design is to optimise fit and fill of the femur, which allows maximal contact of bone to the surfaces available for ingrowth, and optimises the initial stability of the femoral component. Failure to achieve initial stability is a major cause of early failure in revision THR. ${ }^{28}$ Proximally HA-coated press-fit femoral components have been shown to achieve early fixation ${ }^{7}$ and have superior bone ingrowth in the revision setting compared to non-HA-coated components. ${ }^{29}$ They also optimise stress transfer to the proximal femur, with minimal micromovement. ${ }^{30,31}$

All femoral components used in this study had a collar with a smooth superior surface and an undersurface coated with HA. Our rationale for using a collar was to reduce the risk of subsidence because collars have been shown to limit migration of the femoral component in patients with poor bone stock ${ }^{13}$ and improve loading of the proximal femur when bony contact is achieved. ${ }^{16}$ A lateral flare was also added to all components to minimise axial migration, further enhancing stability. The benefit conferred by collars is controversial, particularly in the revision setting, where bone stock might be deficient. ${ }^{32-34}$ The individual design of each component, and the fact that these patients were having first-time revisions, meant that we were able to achieve collar-bone contact in most cases. Iatrogenic factors such as bone loss during extraction of the component and variation from the planned neck osteotomy were usually responsible when this contact was not achieved (Fig. 2). In these situations the flared design of the body contributed to obtaining stability.

These femoral components were designed to attain immediate stability as well as minimise the risk of fractures to the proximal femur. Pre-operative planning focused on 
achieving the best line-to-line fit in the metaphyseal region of the femur. Attempts to achieve optimal fill of the metaphysis could lead to a bulky prosthesis, which reduces the chances of bone regeneration and increases the risk of fracture. In cases where metaphyseal bone was deficient, the best diaphyseal fit was achieved. In patients with Paprosky type 3 femoral bone defects, long fully HA-coated components with distal cutting flutes were used. Similar designs with flutes have been shown, in experimental studies to maximise torsional stability. ${ }^{17,18}$ These components require a minimum of $6 \mathrm{~cm}$ of intimate bone-implant contact below the distal extent of an osteolytic lesion to achieve satisfactory stability. ${ }^{14}$ Stem design in the revision setting therefore requires some flexibility. One factor which facilitated the use of this design was that these patients had relatively well preserved proximal femoral bone stock.

Sotereanos et $\mathrm{al}^{14}$ reported improved hip scores with no revisions at a mean of 5.3 years using custom-made femoral components. The design of their prosthesis was markedly different and based on a different philosophy to ours. Their series was smaller and the patients had different pathologies, each having had a mean of three previous procedures and having a Paprosky grade IIIB or IV proximal femoral defect. Their patients were therefore in a higher risk group, so it is difficult to compare their results with ours.

Although there have been few studies examining the use of custom-made femoral components for revision THR, authors have used several uncemented off the shelf designs with varying success. Mulliken et $\mathrm{al}^{35}$ reported a $40 \%$ periprosthetic fracture rate, relatively modest improvement in the Harris hip score and inadequate fixation using proximally porous-coated femoral components in the short term. Results of extensively porous-coated components have been more encouraging, with excellent clinical and radiographic results at a mean of 6.5 years follow-up. ${ }^{26}$ This study had a smaller cohort than that of Mulliken et al, ${ }^{35}$ and their patients had better-preserved femoral bone stock. Excellent long-term results have been reported with fully HA-coated components, with only three failures in 40 complex revision cases at follow-up of a mean of 10.2 years. ${ }^{36}$ Garbuz et al ${ }^{37}$ reported decreased pain and improved quality of life scores following revision THR using tapered, fluted modular titanium femoral components.

The National Institute of Health consensus group have stated that satisfactory implants are those with ten-year survival figures of at least $95 \% .{ }^{38}$ Our results suggest that CAD-CAM femoral components can be successfully used as revision prostheses. Reporting the outcome of a single component has been shown to be valid. ${ }^{39,40}$

Despite the encouraging results achieved with these components, some important points need to be considered. The high degree of anatomical conformity of these uncemented components means that their optimal fit and ultimate success depend on highly accurate, reproducible surgical technique, which needs to be acquired prior to undertaking this type of surgery. ${ }^{41}$
Cost is also an issue. Each revision CAD-CAM component costs about $£ 1800$. Optional off the shelf systems are available with adjuncts such as cables and plates. A direct comparison of costs with contemporary prostheses is difficult because of the wide variety of systems in common use, as reported by the United Kingdom National Joint Registry, ${ }^{1}$ as well as other adjuncts used in revision procedures, including cables, plates, bone grafts and extraction equipment.

Since the advent of the custom-made components described in this study, encouraging medium-term results have been reported with the use of extensively porous-coated components, ${ }^{26}$ the ZMR (Zimmer) porous-coated modular stem $^{42}$ and fully HA-coated long-stemmed components. ${ }^{43}$ Many of these contemporary prostheses are versatile and can be applied to most revision situations, including those with deficient proximal bone stock where the design described in this study would be unsuitable. It is therefore difficult to propose the routine use of custom-made CAD-CAM components for revision THR in the current environment.

These minimum ten-year follow-up results are encouraging and compare favourably with revision prostheses using other means of fixation. They suggest that these custommade implants provide a viable option in revision THR in suitable cases, particularly where the anatomy of the proximal femur makes the use of a monobloc or modular off the shelf system unsuitable.

No benefits in any form have been received or will be received from a commercial party related directly or indirectly to the subject of this article.

\section{References}

1. No authors listed. www.njrcentre.org.uk (date last accessed 16 August 2010).

2. Kavanagh BF, Ilstrup DM, Fitzgerald RH Jr. Revision total hip arthroplasty. $J$ Bone Joint Surg [Am] 1985;67-A:517-26.

3. Pellicci PM, Wilson PD Jr, Sledge CB, et al. Long-term results of revision total hip replacement: a follow-up report. J Bone Joint Surg [Am] 1985;67-A:513-16.

4. Izquierdo RJ, Northmore-Ball MD. Long-term results of revision hip arthroplasty: survival analysis with special reference to the femoral component. J Bone Joint Surg [Br] 1994;76-B:34-9.

5. Mulroy WF, Harris WH. Revision total hip arthroplasty with use of so-called second-generation cementing technqiues for aseptic loosening of the femoral component: a fifteen-year-average follow-up study. J Bone Joint Surg [Am] 1996;78A:325-30.

6. Pierson JL, Harris WH. Cemented revision for femoral osteolysis in cemented arthroplasties: results in 29 hips after a mean 8.5-year follow-up. J Bone Joint Surg [Br] 1994;76-B:40-4.

7. Raut VV, Siney PD, Wroblewski BM. Cemented Charnley revision arthroplasty for severe femoral osteolysis. J Bone Joint Surg [Br] 1995;77-B:362-5.

8. Springer BD, Fehring TK, Griffin WL, Odum SM, Masonis TL. Why revision total hip arthroplasty fails. Clin Orthop 2009;407:166-73.

9. Bardou-Jacquet J, Souillac V, Mouton A, Chauveaux D. Primary aseptic revision of the femoral component of a cemented total hip arthroplasty using a cemented technique without bone graft. Orthop Traumatol Surg Res 2009;95:243-8.

10. Nouri H, Kallel S, Slimane MIT, et al. Revision total hip arthroplasty with cemented femoral component. Eur J Orthop Surg Traumatol 2008;18:327-32.

11. Peters CL, Rivero DP, Kull LR, et al. Revision total hip arthroplasty without cement: subsidence of proximally porous-coated femoral components. J Bone Joint Surg [Am] 1995;77-A:1217-26.

12. Morrey BF, Kavanagh BF. Complications with revision of the femoral component of total hip arthroplasty: comparison between cemented and uncemented techniques. J Arthroplasty 1992;7:71-9.

13. Walker PS, Culligan SG,I Hua J, Muirhead-Allwood SK, Bentley G. Stability and bone preservation in custom designed revision hip stems. Clin Orthop 2000;373:164-73 
14. Sotereanos N, Sewecke J, Raukar GJ, et al. Revision total hip arthroplasty with a custom cementless stem with distal cross-locking screws: early results in femora with large proximal segmental deficiencies. J Bone Joint Surg [Am]2006;88-A:1079-84.

15. Pak JH, Paprosky WG, Jablonsky WS, Lawrence JM. Femoral strut allografts in cementless revision total hip arthroplasty. Clin Orthop 1993;295:172-8.

16. Oh I, Harris WH. Proximal strain distribution in the loaded femur: an in vitro comparison of the distributions in the intact femur and after insertion of different hip-replacement femoral components. J Bone Joint Surg [Am] 1978;60-A:75-85.

17. Kendrick JB 2nd, Noble PC, Tullos HS. Distal stem design and the torsional stability of cementless femoral stems. J Arthroplasty 1995;10:463-9.

18. Whiteside LA, Arima J, White SE, Branam L, McCarthy DS. Fixation of the mod ular total hip femoral component in cementless total hip arthroplasty. Clin Orthop 1994:298:184-90

19. Dawson J, Fitzpatrick R, Carr A, Murray D. Questionnaire on the perception of patients about total hip replacement. J Bone Joint Surg [Br] 1996;78-B:185-90.

20. Harris WH. Traumatic arthritis of hip after dislocation and acetabular fractures: treatment by mold arthroplasty: an end-result study using a new method of result evaluation. J Bone Joint Surg [Am] 1969;51-A:737-55.

21. Klässbo M, Larsson $\mathbf{E}$, Mannerik E. Hip disability and osteoarthritis outcome score: an extension of the Western Ontario and McMaster Universities Osteoarthritis Index. Scand J Rheumato/ 2003;32:46-51.

22. Engh CA, Massin P, Suthers KE. Roentgenographic assessment of the biologic fixation of porous-surfaced femoral components. Clin Orthop 1990;257:107-28.

23. Gruen TA, McNeice GM, Amstutz HC. "Modes of failure" of cemented stem-type femoral components: a radiographic analysis of loosening. Clin Orthop 1979;141:17-27.

24. DeLee JG, Charnley J. Radiological demarcation of cemented sockets in total hip replacement. Clin Orthop 1976;121:20-32.

25. Brooker AF, Bowerman JW, Robinson RA, Riley LH Jr. Ectopic ossification following total hip replacement: incidence and a method of classification. J Bone Joint Surg [Am] 1973;55-A:184-90.

26. Moon KH, Kang JS, Lee SH, Jung SR. Revision total hip arthroplasty using an extensively porous coated femoral stem. Clin Orthop Surg 2009;1:105-9.

27. Noble PL, LindahI LJ, Jay JL, Davidson J, Tullos HS. Analysis of design variables for optimizing the fit of press-fit femoral stem. Orthop Trans 1986;10:398.

28. Springer BD, Fehring TK, Griffin WL, Odum SM, Masonis JL. Why revision total hip arthroplasty fails. Clin Orthop 2009;467:166-73.

29. Bolognesi MP, Pietrobon R, Clifford PE, Vail TP. Comparison of a hydroxyapatitecoated sleeve and a porous-coated sleeve with a modular revision hip stem: a prospective, randomized study. J Bone Joint Surg [Am] 2004;86-A:2720-5.
30. Geesink RG, Hoefnagels NH. Six-year results of hydroxyapatite-coated total hip replacement. J Bone Joint Surg [Br] 1995;77-B:534-47.

31. Kärrholm J, Malchau H, Snorrason F, Herberts P. Micromotion of femoral stems in total hip arthroplasty: a randomized study of cemented, hydroxyapatite-coated, and porous-coated stems with roentgen stereophotogrammetric analysis. J Bone Joint Surg [Am] 1994;76-A:1692-705.

32. Cheng SK, Davey JR, Inman RD, Binnington AG, Smith TJ. The effect of the medial collar in total hip arthroplasty with porous-coated components inserted without cement: an in vivo canine study. J Bone Joint Surg [Am] 1995;77-A:118-23.

33. Caglar O, Atilla B, Tokgozoglu M, Alpaslan M. The effect of collar on asceptic loosening and proximal femoral femoral bone resorption in hybrid total hip arthroplasty. Orthopaedics 2008;31:227.

34. Whiteside LA. Easley JC. The effect of collar and distal stem fixation on micromotion of the femoral stem in uncemented total hip arthroplasty. Clin Orthop 1989;239:145-53.

35. Mulliken BD, Rorabeck CH, Bourne RB. Uncemented revision total hip arthroplasty: a 4-to-6-year review. Clin Orthop 1996;325:156-62.

36. Mahoney OM, Kinsey TL, Asayama I. Durable fixation with a modern fully hydroxyapatite-coated long stem in complex revision total hip arthroplasty. J Arthroplasty 2010;25:355-62.

37. Garbuz DS, Toms A, Masri BA, Duncan CP. Improved outcome in femoral revision arthroplasty with tapered fluted modular titanium stems. Clin Orthop 2006:453:199202

38. No authors listed. Total hip replacement. NIH Consensus Statement 1994;12:1-31

39. Galante J. Evaluation of results of total hip replacement. J Bone Joint Surg [Am] 1990;72-A:159-60

40. Poss R, Clark CR, Heckman JD. A concise format for reporting the longer-term follow-up status of patients managed with total hip arthroplasty. J Bone Joint Surg [Am] 2001;83-A:1779-81.

41. Stulberg SD, Stulberg BN, Wixson RL. The rationale, design characteristics, and preliminary results of a primary custom total hip prosthesis. Clin Orthop 1989;249:79-96.

42. Lakstein D, Backstein D, Safir O, Kosashvili Y, Gross AE. Revision total hip arthroplasty with a porous-coated modular stem: 5 to 10 years follow-up. Clin Orthop 2010;468:1310-15

43. Raman R, Kamath RP, Parikh A, Angus PD. Revision of cemented hip arthroplasty using hydroxyapatite-ceramic-coated femoral component. J Bone Joint Surg [Br] 2005;87-B:1061-7.

44. Trikha SP, Singh S, Raynham OWT, et al. Hydroxyapatite-ceramic-coated femoral stems in revision hip surgery. J Bone Joint Surg [Br] 2005;87-B:1055-60. 